\title{
Treatment choice in acute rheumatic carditis
}

\author{
D G HUMAN, I D HILL, AND C B FRASER \\ Department of Paediatrics and Child Health, University of Cape Town, Red Cross War Memorial Children's \\ Hospital, Cape Town, South Africa.
}

SUMMARY A trial was conducted using sequential analysis by pairs to compare the efficacy of corticosteroids and salicylates in the treatment of acute rheumatic carditis. The results show a significantly favourable effect of steroid treatment both in clinical response and in reduction of the erythrocyte sedimentation rate. In addition, patients receiving steroids usually had a shorter hospital stay. The use of steroids in acute rheumatic fever with carditis is recommended.

While the decline in rheumatic fever and rheumatic heart disease is a phenomenon of the developed world, in Africa and Asia the disease is still an important cause of mortality and morbidity. ${ }^{1}$ The place of corticosteroids in the treatment of acute rheumatic carditis remains unclear despite more than 20 years of use in clinical practice. Most authorities now endorse the use of steroids in patients with moderate to severe carditis, ${ }^{2-4}$ although some still claim that steroids have no place in the treatment of acute rheumatic carditis. ${ }^{5}$ This study was designed to compare the efficacy of steroids and salicylates in the management of acute rheumatic carditis.

\section{Patients and methods}

All children presenting to the Red Cross War Memorial Children's Hospital with features of acute rheumatic fever were referred to a member of the cardiology unit. Those patients fulfilling the following criteria were included in the study:

(1) The presence of acute rheumatic fever as defined by the modified Jones' criteria ${ }^{6}$ (Table 1).

(2) Evidence of acute carditis (Table 2).

(3) No steroids or salicylates given in the preceding two weeks.

The study began in June 1981 and was completed in September 1982.

A clinical scoring system was used to grade the severity of cardiac disease at the time of hospital admission. Congestive cardiac failure of a mild degree (that is, audible gallop rhythm, raised venous pressure, or hepatic enlargement of less than $3 \mathrm{~cm}$ and minimal cardiac enlargement) was allocated one point and more severe failure (that is, palpable
Table 1 Jones' criteria (revised)

\begin{tabular}{lc}
\hline Major manifestations & Minor manifestations \\
\hline Carditis & Clinical \\
Polyarthritis & Fever \\
Chorea & Arthralgia \\
Erythema marginatum & Previous rheumatic fever or \\
Subcutaneous nodules & rheumatic heart disease \\
& Laboratory \\
& Acute phase reaction \\
& Erythrocyte sedimentation rate \\
& C reactive protein \\
PLUS & Leukocytosis \\
Supporting evidence of preceding stroptococcal infection & Prolonged PR interval \\
\hline
\end{tabular}

The presence of two major criteria, or of one major and two minor criteria, indicates a high probability of rheumatic fever.

Table 2 Features of rheumatic carditis

\begin{tabular}{ll}
\hline (1) Murmurs & $\begin{array}{l}\text { (a) Significant apical systolic murmur, apical } \\
\text { diastolic murmur, or basal diastolic murmur } \\
\text { without a previous history of rheumatic fever }\end{array}$ \\
& $\begin{array}{l}\text { (b) Change in the character of a murmur, or } \\
\text { development of a new murmur with a } \\
\text { previous history of rheumatic fever }\end{array}$ \\
(2) Cardiomegaly & \\
(3) Pericarditis &
\end{tabular}

gallop rhythm, considerably raised venous pressure, clinically obvious cardiomegaly) two points. Valvular disease was allocated one point for a typical organic murmur of grade $3 / 6$ or less, and two points if a 'thrill' was present. The total number of valves affected was also added to the score. A pericardial friction rub was allocated two points if present. In this way patients could be matched according to their clinical score and were assigned to one of three groups. Group 1 comprised those with moderate 
disease (score 1 to 5), group 2 those with severe disease (score 6 to 10), and group 3 those with life threatening carditis (score 11 to 16). All the patients had evidence of an affected mitral valve, and most had had symptoms (chest pain, dyspnoea, lethargy) for two weeks or less. Patients in each group were alternatively assigned to treatment with either steroids (prednisone $3 \mathrm{mg} / \mathrm{kg} /$ day for 10 days and then a reducing dosage for a further 10 days) or salicylates (soluble aspirin $100 \mathrm{mg} / \mathrm{kg} / \mathrm{day}$ for 20 days). All patients received oral penicillin $250 \mathrm{mg} 6$ hourly for 10 days with subsequent intramuscular penicillin for long term prophylaxis, while digoxin and diuretics were used when indicated.

The patients were cared for in general paediatric wards and were regularly assessed by one of the cardiologists. Clinical response to treatment was identified by a fall in the sleeping pulse to below 80 beats/minute and a decline of at least one point in the clinical score. The erythrocyte sedimentation rate (Westergren method) was monitored twice weekly and a value below $30 \mathrm{~mm}$ in the first hour was accepted as a response to treatment. The number of days taken to achieve clinical response to treatment, the time for the erythrocyte sedimentation rate to return to normal, and the total length of stay in hospital were recorded for each patient.

Each pair of patients was compared for the time taken to achieve a clinical response, the time taken for the erythrocyte sedimentation rate to fall below $30 \mathrm{~mm}$ in the first hour, and the total duration of stay in hospital. The results were assessed using the method of sequential analysis by pairs. ${ }^{7}$

\section{Results}

A total of 24 patients were studied (12 pairs) 22 of whom had moderate disease and two severe disease. There were no cases of life threatening carditis during the 12 months of the survey. Individual details of the patients are shown in Table 3 .

In the method of sequential analysis by pairs each patient receiving steroids was compared directly with a patient receiving salicylates, the pair groups having been decided at the time of admission to the trial. There was noticeable preference for steroid treatment -10 pairs showing a more rapid clinical response by at least five days, and two pairs showing equally rapid responses. In no case was the response more rapid with salicylates and this result is statistically significant $(\mathrm{P}<0 \cdot 05)$. The response of the erythrocyte sedimentation rate showed a similar preference for steroid treatment; 9 pairs showing a fall to less than $30 \mathrm{~mm}$ in the first hour at least five days earlier, with two pairs showing equally rapid responses and the remaining pair having a prolonged response time. In no case was the response more rapid with salicylate, and this result was also significant at the $\mathrm{P}<0.05$ level.

The duration of hospital stay was similar in four patient pairs who received salicylates or steroids with good response. In the 8 patients who failed to respond to the initial salicylate treatment steroids were used subsequently and their hospital stay reflects the therapeutic effect of both regimens. Five patients who received steroids as initial treatment had a shorter hospital stay by at least five days and

Table 3 Details of 12 pairs of patients with acute rheumatic carditis

\begin{tabular}{|c|c|c|c|c|c|c|c|c|c|c|c|c|}
\hline & \multicolumn{6}{|c|}{ Salicylate treatment } & \multicolumn{6}{|c|}{ Steroid treatment } \\
\hline & \multicolumn{3}{|c|}{ On admission } & \multicolumn{3}{|l|}{ Treatment } & \multicolumn{3}{|c|}{ On admission } & \multicolumn{3}{|l|}{ Treatment } \\
\hline & $\begin{array}{l}\text { Clinical } \\
\text { score }\end{array}$ & $E S R$ & $\begin{array}{l}\text { Other } \\
\text { signs }\end{array}$ & $\begin{array}{l}\text { Clinical } \\
\text { response } \\
\text { (days) }\end{array}$ & $\begin{array}{l}\text { ESR } \\
\text { response } \\
\text { (days) }\end{array}$ & $\begin{array}{l}\text { Hospital } \\
\text { stay } \\
\text { (days) }\end{array}$ & $\begin{array}{l}\text { Clinical } \\
\text { score }\end{array}$ & $E S R$ & $\begin{array}{l}\text { Other } \\
\text { signs }\end{array}$ & $\begin{array}{l}\text { Response } \\
\text { (days) }\end{array}$ & $\begin{array}{l}E S R \\
\text { response } \\
\text { (days) }\end{array}$ & $\begin{array}{l}\text { Hospital } \\
\text { stay } \\
\text { (days) }\end{array}$ \\
\hline \multicolumn{13}{|l|}{ Group I } \\
\hline Pair 1 & 3 & 85 & $\begin{array}{l}\text { Chorea, } \\
\text { nodules }\end{array}$ & NR & NR & 30 & 5 & 110 & - & 9 & 30 & 42 \\
\hline Pair 2 & 3 & 135 & Arthritis & 11 & NR & 37 & 3 & 70 & - & 11 & 15 & 39 \\
\hline Pair 3 & 5 & 60 & - & NR & NR & $49^{\circ}$ & 5 & 116 & Arthritis & 16 & 7 & 41 \\
\hline Pair 4 & 3 & 121 & - & NR & NR & $57^{\circ}$ & 4 & 87 & - & 15 & 16 & 29 \\
\hline Pair 5 & 3 & 115 & _- & 20 & 14 & 24 & 2 & 91 & $\ldots$ & 13 & 14 & 23 \\
\hline Pair 6 & 4 & 78 & - & 25 & 22 & 38 & 3 & 110 & $\ldots$ & 9 & 9 & 33 \\
\hline Pair 7 & 3 & 130 & - & NR & NR & $73^{\circ}$ & 5 & 40 & - & 20 & 6 & 100 \\
\hline Pair 8 & 4 & 129 & - & NR & NR & $60^{\circ}$ & 4 & 50 & Chorea & 15 & 6 & 25 \\
\hline Pair 9 & 4 & 120 & Arthritis & NR & NR & $90^{\circ}$ & 3 & & - & 9 & 9 & 23 \\
\hline Pair 10 & 4 & 50 & - & 21 & 12 & 22 & 4 & 80 & Pyrexia & 15 & 10 & 22 \\
\hline Pair 11 & 3 & 120 & Arthritis & 10 & NR & $47^{\circ}$ & 3 & 150 & Arthritis & 14 & 14 & 44 \\
\hline $\begin{array}{l}\text { Group II } \\
\text { Pair 1 }\end{array}$ & 8 & 44 & - & NR & NR & $75^{\circ}$ & 7 & 90 & - & 14 & 10 & 42 \\
\hline
\end{tabular}

$\mathrm{NR}=$ no response; ESR erythrocyte sedimentation rate in 1 hour.

Subsequently received steroid treatment. 
in three pairs the stay was similar. There was therefore a trend towards a shorter hospital stay in the steroid treated pairs but a significant difference cannot be shown probably because of the introduction of steroids to some of those initially treated with salicylate.

\section{Discussion}

The accurate assessment of a clinical response to treatment is difficult. To obtain objectivity documentation of the sleeping pulse rate, the erythrocyte sedimentation rate, and a clinical scoring system were used at the time of hospital admission and during repeated examinations. Initial assessments were checked by two cardiologists and subsequent examinations were performed by an experienced cardiologist who had no direct role in decisions of patient management. Thus, although the examiner was aware of the treatment programme, there was no inherent bias in recording the response.

Symptoms of carditis had been present for only a few days in most patients and there was no apparent difference in response in those whose presenting illness had been more prolonged. In 7 patients, five of whom had residual heart disease, there was a previous history of rheumatic fever. The initial response to treatment was rapid in four patients (three on steroids and one on salicylates), although two had a prolonged course subsequently. The other patient received salicylates and failed to respond.

The results show an unequivocal beneficial effect of prednisone in the treatment of acute rheumatic carditis. The time taken to achieve a clinical improvement and reduce the erythrocyte sedimentation rate was significantly shorter in those on steroids and it is highly likely that this method of treatment decreases the total duration of stay in hospital.

At present steroids are only recommended for patients with moderate to severe carditis and it is unclear why they should be denied to those with milder forms of the disease. Reasons for withholding steroids include an unacceptably high incidence of serious complications relating to treatment or long term adverse effects on rheumatic heart disease. None of the patients in this study had serious side effects related to steroid treatment and although all showed slight weight gain and evidence of 'cushingoid' facies, this resolved within one month of stopping treatment. Furthermore the Combined rheumatic fever group study ${ }^{89}$ comparing prednisone and salicylate treatment showed no difference in the long term outcome of rheumatic heart disease. Other trials have suggested marginal benefit from steroid treatment ${ }^{10}$ and there is no evidence that patients treated with steroids fare worse than others.

An increased surgical risk for valve replacement after steroid treatment has been cited as a contraindication to their use. ${ }^{5}$ The operative mortality for mitral valve replacement at our hospital is less than $5 \%$ and most patients had rheumatic heart disease. ${ }^{11}$ The results obtained for emergency valve replacement in acute rheumatic fever without the prior use of steroids show no improvement on these figures. (Kinsley RH. Annual Report 1982, Division of Cardio-thoracic Surgery, University of the Witwatersrand). Rebound of the erythrocyte sedimentation rate on stopping steroids is common and is cited as an indication for salicylate. Most patients in this study, however, showed no initial erythrocyte sedimentation rate response to salicylates so there would seem little justification for combined or sequential treatment with salicylates and steroids. The role of salicylates in the treatment of rheumatic carditis requires reassessment. Experimental evidence suggests that salicylates may have a deleterious effect on cardiac metabolism ${ }^{12}$ and may be contraindicated in active carditis. That five of 12 patients in this study who received salicylates initially went on to have severe, persisting carditis and a hospital stay greater than 50 days is noteworthy. In contrast only one patient receiving prednisone had a stay over 50 days.

The optimal duration of steroid treatment remains unresolved. The first three pairs (two in group 1 and one in group 2) received short initial courses (prednisone $3 \mathrm{mg} / \mathrm{kg} /$ day for 10 days or soluble aspirin $100 \mathrm{mg} / \mathrm{kg} /$ day for 10 days) and all showed an incomplete response (Table 3 ). Thereafter the duration of treatment was increased to 20 days and among those initially receiving prednisone there was only one clinical and erythrocyte sedimentation rate relapse necessitating treatment. Most patients on steroids showed a transient rebound of the erythrocyte sedimentation rate to values above $30 \mathrm{~mm}$ in the first hour but without worsening of clinical signs. All were successfully managed solely with bedrest and 'anti-failure' treatment as indicated. A trial to evaluate varying dosages and duration of steroid treatment is currently under way.

\section{Conclusion}

It is recommended that all patients with active rheumatic fever with carditis receive steroid treatment. The results of this study show that the severity of the acute illness is reduced more rapidly than with salicylate and there is a definite trend towards a shorter hospital stay. 
We thank Dr M Mann for advice on statistical methods. Dr $\mathrm{R}$ McDonald for review of the manuscript, and Dr J G L Strauss, Medical Superintendent for permission to publish. Miss K Leahy and Ms K Malan provided expert help in the preparation of the manuscript.

\section{References}

1 Discascio G. Taranta A. Rheumatic fever in children. Am Heart $J$ 1980;99:635-58.

2 Nadas AS. Fyler DC. Pediatric cardiology, 3rd ed. Philadelphia: WB Saunders, 1972.

3 Wannamaker LW, Kaplan EL. Acute rheumatic fever. In: Moss AS. Adams FH, Emmanouilides GC. eds. Heart disease in infants, children and adolescents. 2nd ed. Baltimore: Williams and Wilkins. 1977.

+ Oakley CM. Acute rheumatic carditis. In: Borman JB, Gotsman MS. Rheumatic valvular disease in children. Berlin: Springer-Verlag, 1980.

5 Barlow JB. Valvular heart disease in South Africa. South African Journal of Continuing Medical Education 1983:1:7-13.

- Markowitz M. Gordis L. Rheumatic fever. 2nd ed. Philadelphia: WB Saunders, 1972:247.

${ }^{7}$ Armitage P. Sequential inedical trials. London: Blackwell, 1975.
${ }^{8}$ Combined rheumatic fever study group. A comparison of short-term intensive prednisone and acetysalicylic acid therapy in the treatment of acute rheumatic fever. $N$ Engl $J$ Med 1965;272:63.

${ }^{9}$ UK and USA joint report. The natural history of rheumatic fever and rheumatic heart disease. 10 year report of a co-operative clinical trial of $\mathrm{ACTH}$, corticone and aspirin. Circulation 1965;32:457-76.

${ }^{10}$ Czoniczer G, Anezwa F, Pelargonio S, et al. Therapy of severe rheumatic carditis. Comparison of adrenocortical steroids and aspirin. Circulation 1964;29:813-9.

1 Human DG, Joffe HS, Fraser CB, Barnard CN. Mitral valve replacement in children. J Thorac Cardiovasc Surg 1982;83: 873-7.

12 Vercesi AE, Focesi A. The effects of salicylate and aspirin on the activity of phospharylase $\mathrm{A}$ in perfused hearts of rats. Experientia 1977;33:157-8.

Correspondence to Dr D G Human, Cardiology Unit, Red Cross War Memorial Children's Hospital, Rondebosch 7700, Cape Town, South Africa.

Received 25 January 1984 